Revista Brasileira de Agricultura Irrigada v.14, no .4, p. 4128 - 4140, 2020

ISSN 1982-7679 (On-line)

Fortaleza, CE, INOVAGRI - http://www.inovagri.org.br

DOI: $10.7127 /$ rbai.v14n401177

Protocolo 1177.20 - 27/08/2020 Aprovado em 29/11/2020

\title{
ENTUPIMENTO E MODIFICAÇÃO DA VAZÃO DE EMISSORES APLICANDO DILUIÇÃO DE ÁGUA PRODUZIDA DE PETRÓLEO TRATADA
}

Antonio Diego da Silva Teixeira ${ }^{1}$, Hudson Salatiel Marques Vale ${ }^{2}$, Danniely de Oliveira Costa ${ }^{3}$, Silvanete Severino da Silva ${ }^{4}$, Ayslann Todayochy Siqueira de Andrade ${ }^{5}$, Rafael Oliveira Batista ${ }^{6}$

\section{RESUMO}

O tratamento e a diluição da água produzida do petróleo são duas técnicas que possibilitam a redução do potencial poluidor deste resíduo, bem como do seu risco de obstrução de emissores, caso possa ser utilizado para fins de reuso agrícola restrito. Objetivou-se, com este trabalho, analisar o risco de obstrução de emissores, bem como a modificação da vazão de emissores aplicando diluição de água produzida tratada em água subterrânea na proporção 1:10. Utilizou-se o delineamento inteiramente casualizado e esquematizado com parcelas subdivididas, em três repetições; as parcelas continham três tipos de emissores não autocompensantes (E1 - Netafim Super Typhoon, E2 - Netafim Streamline e E3 - NaanDanJain TalDrip) e nas subparcelas os tempos de avaliação da vazão dos emissores (0, 20, 40, $60,80,100,120,140$ e 160 h). A vazão dos emissores e os atributos físico-químicos e microbiológicos da diluição de água produzida tratada foram obtidos a cada 20 e $80 \mathrm{~h}$, respectivamente, durante o período operacional total de $160 \mathrm{~h}$. Os atributos $\mathrm{pH}$, cálcio e sólidos dissolvidos totais representaram risco severo de entupimento de gotejadores com agentes químicos. A maior suscetibilidade ao entupimento foi verificada para o gotejador E2, devido, provavelmente, ao seu menor comprimento de labirinto aliado à formação de incrustação no gotejador. O gotejador E3 é o mais recomendado na operação com água produzida tratada diluída na proporção de 1:10.

Palavras-chave: Recursos hídricos, microirrigação, resíduo industrial, desempenho hidráulico.

\footnotetext{
${ }^{1}$ Eng. Agrícola e Ambiental, Universidade Federal Rural do Semi-Árido, CEP: 59625-900, Campus Mossoró, MossoróRN, Brasil. E-mail: diego.itap@hotmail.com

2 Doutor em Manejo de Solo e Água, Universidade Federal Rural do Semi-Árido, CEP: 59625-900, Campus Mossoró, Mossoró- RN, Brasil. E-mail: klaus_angel@hotmail.com

${ }^{3}$ Doutora em Manejo de Solo e Água, Universidade Federal Rural do Semi-Árido, CEP: 59625-900, Campus Mossoró, Mossoró- RN, Brasil. E-mail: danniely_oliveira@ hotmail.com

${ }^{4}$ Profa. Doutora em Engenharia Agrícola, Universidade Federal Rural do Semi-Árido, CEP: 59625-900, Campus Mossoró, Mossoró- RN, Brasil. E-mail: silvanete.silva@ufersa.edu.br

${ }^{5}$ Mestre em Manejo de Solo e Água, Universidade Federal Rural do Semi-Árido, CEP: 59625-900, Campus Mossoró, Mossoró- RN, Brasil. E-mail: ayslan_@hotmail.com

${ }^{6}$ Prof. Doutor em Engenharia Agrícola, Universidade Federal Rural do Semi-Árido, CEP: 59625-900, Campus Mossoró, Mossoró- RN, Brasil. E-mail: rafaelbatista@ufersa.edu.br
} 


\title{
CLOGGING AND MODIFICATION OF THE EMITTERS FLOW RATE APPLYING DILUTION OF TREATED WATER PRODUCED BY OIL EXPLORATION
}

\begin{abstract}
The treatment and dilution of water produced from oil are two techniques that make it possible to reduce the polluting potential of this waste, as well as its risk of obstructing emitters, if it can be used for purposes of restricted agricultural reuse. The objective of this work was to analyze the risk of obstruction of emitters, as well as to modify the flow rate of emitters by applying dilution of water produced from oil treated in groundwater (1:10). A completely randomized design and split plot scheme was used, in three replications; the plots contained three types of non-self-compensating emitters (E1 - Netafim Super Typhoon, E2 - Netafim Streamline and E3 - NaanDanJain TalDrip) and in the subplots the flow rate evaluation times of the emitters $(0,20,40,60,80,100,120,140$ and 160 h). The emitters flow rate and the physical-chemical and microbiological attributes of the dilution of treated water produced were obtained every 20 and $80 \mathrm{~h}$, respectively, during the total operational period of $160 \mathrm{~h}$. The attributes $\mathrm{pH}$, calcium and total dissolved solids represented a severe risk of clogging of drippers with chemical agents. The greater susceptibility to clogging was found for the E2 dripper, probably due to its shorter labyrinth length combined with the formation of fouling on the dripper. The E3 dripper is the most recommended when operating with diluted treated produced water, in the proportion of 1:10.
\end{abstract}

Keyword: Water resources, microirrigation, industrial waste, hydraulic performance.

\section{INTRODUÇÃO}

Tendo como base, a necessidade de aumento na produtividade agrícola, o método da irrigação localizada apresenta diversas vantagens em relação aos demais métodos, pois possibilita grande economia de água, baixo consumo de energia elétrica e reduzida mão de obra. Entre os sistemas de microirrigação ou irrigação localizada destaca-se o sistema de irrigação por gotejamento pelo baixo custo de mão de obra e energia e elevada eficiência de aplicação da água (BISCARO, 2014).

Entretanto, os principais problemas operacionais do sistema de irrigação por gotejo estão relacionados ao entupimento, causado pelo tratamento inadequado da água de irrigação, provocando obstrução dos emissores e diminuindo a disponibilidade de operação do sistema devido à necessidade de limpeza da tubulação e, ou substituição dos emissores (TESTEZLAF, 2017), o que pode gerar custos excessivos de operacionalização.

Dois importantes impactos, resultantes do entupimento dos emissores de sistemas de irrigação por gotejamento, são o aumento (MESQUITA et al., 2016a,b; VALE et al., 2018a,b) e a redução (FERNANDES et al., 2014; MARQUES et al., 2016) da vazão de projeto, que interfere diretamente na uniformidade de distribuição de água.

A água que se origina da extração do petróleo e gás é denominada água produzida e representa um dos maiores fluxos de água residuária gerados na indústria do petróleo e gás (DICKHOUT et al., 2017). Além disso, o gerenciamento desse efluente é um grande desafio, por causa dos impactos ambientais e dos custos elevados gerados (JIMÉNEZ et al., 2017).

No Semiárido brasileiro, os primeiros estudos com água produzida tratada, para fins de irrigação, ocorreram de 2012 a 2014, no Campo da Fazenda Belém, da Unidade de Produção do Rio Grande do Norte e Ceará, instalado em Aracati-CE, pertencente ao ativo de produção de petróleo de Mossoró-RN. A água produzida do petróleo, nestes locais, foi tratada por filtração e osmose inversa, sendo posteriormente utilizada na irrigação de girassol e mamona. (MIRANDA et al., 2016; WEBER et al., 2017).

Devido à toxicidade da água produzida do petróleo (mesmo com tratamento), as 
recomendações dos tipos de cultivos agrícolas que possam ser produzidos com essa água, ainda são limitadas. No trabalho de Andrade et al. (2011), recomenda-se para a água produzida tratada, cultivos agrícolas não comestíveis, tais como as oleaginosas para produção de biocombustível (girassol, soja e mamona) e o girassol ornamental.

No trabalho de Miller et al. (2020) são apresentadas concentrações muito elevadas de cálcio $\left(39,22 \mathrm{mmol}_{\mathrm{c}} \mathrm{L}^{-1}\right)$, magnésio $(8,81$ $\left.\mathrm{mmol}_{\mathrm{c}} \mathrm{L}^{-1}\right)$, condutividade elétrica $\left(49 \mathrm{dS} \mathrm{m}^{-1}\right)$, sólidos dissolvidos totais $\left(35.900 \mathrm{mg} \mathrm{L}^{-1}\right) \mathrm{e}$ sólidos suspensos totais $\left(271 \mathrm{mg} \mathrm{L}^{-1}\right)$ na água produzida sem tratamento, indicando severo risco de obstrução de emissores por agentes químicos; por esta razão os referidos autores utilizaram pequenas diluições da água produzida do petróleo da ordem de 1 a $5 \%$ na irrigação.

A diluição da água produzida em água subterrânea é uma alternativa que minimiza a obstrução de emissores não autocompensantes. No trabalho realizado por Vale et al. (2020) constatou-se, mitigação do entupimento, nas diluições de $10 \%$ de água produzida em $90 \%$ de água subterrânea e de $20 \%$ de água produzida em $80 \%$ de água subterrânea. A alternativa da diluição em água produzida tratada está relacionada à possibilidade de minimização dos efeitos de redução da qualidade do solo e do desempenho agronômico das plantas, além dos efeitos adversos ao ambiente (MILLER et al., 2020).

Diante o exposto, o presente estudo objetivou analisar o potencial de obstrução e a modificação da vazão de emissores não autocompensantes operando com diluição de água produzida do petróleo tratada coletada em Upanema-RN.

\section{MATERIAL E MÉTODOS}

Este trabalho foi conduzido na área experimental do prédio de Construções Rurais e Ambiência, localizado no campus Leste da Universidade Federal Rural do Semi - Árido (UFERSA) em Mossoró-RN, no período de 26/02 a 10/04 de 2018. Diferentemente do trabalho de Vale et al. (2020) que utilizou água produzida do município de Jucuri-RN, neste estudo os ensaios experimentais foram realizados com água produzida do município de Upanema-RN, com características totalmente diferentes.

A água produzida foi coleta de poços de petróleo do município de Upanema, a qual foi previamente armazenada em um tanque reservatório gradeado, em polietileno de alta densidade e peso molecular, com capacidade para 1000 L. Esta era transportada até a área experimental da UFERSA, sendo depositada em outros reservatórios de polietileno.

Após a coleta, a água produzida foi tratada com polímero de base orgânica. Já a água subterrânea utilizada nos ensaios experimentais foi proveniente de poço tubular gerenciado pela Companhia de Água e Esgoto do Rio Grande do Norte (CAERN). Na Tabela 1 está apresentada uma caracterização físicoquímica da água produzida bruta do município de Upanema-RN.

Tabela 1. Metais presentes na água produzida bruta coleta no município de Upanema-RN

\begin{tabular}{cccccc}
\hline \multicolumn{5}{c}{ Atributos $\left(\mathrm{mg} \mathrm{L}^{-1}\right)$} \\
\hline $\mathrm{Cu}$ & $\mathrm{Zn}$ & $\mathrm{Fe}$ & $\mathrm{Mn}$ & $\mathrm{Pb}$ & $\mathrm{Al}$ \\
0,187 & 0,191 & 1,530 & 1,670 & 0,095 & 1,013 \\
\hline
\end{tabular}

Para a realização dos ensaios experimentais efetuou-se a diluição da água produzida do petróleo tratada à água subterrânea com base nas recomendações propostas por Miller et al. (2020). Optou-se pela diluição 1:10 (uma parte de água produzida para 10 partes de água subterrânea) com o intuito de mitigar os riscos de obstrução químico e biológico de emissores causados pelos atributos Fe e Mn presentes no efluente, conforme relatado por Bucks, Nakayama e Gilbert (1979). Ao usar a diluição de 1:10, 
segundo Bucks, Nakayama e Gilbert (1979), o risco de obstrução de emissores por $\mathrm{Fe}$ e $\mathrm{Mn}$ altera de severo para baixo, indicando redução do risco de obstrução destes atributos (analisar conjuntamente as Tabelas 1 e 2)

$\mathrm{O}$ experimento foi conduzido com Delineamento Inteiramente Casualizado (DIC) em três repetições. Nas parcelas foram distribuídos os três tipos de emissores, a saber: Netafim Super Typhoon (E1), Netafim Streamline (E2) e NaanDanJain TalDrip (E3), enquanto as subparcelas receberam nove tempos para a operação de cada unidade $(0,20$, $40,60,80,100,120,140$ e 160 h).

A bancada experimental foi construída com área superficial de $8 \mathrm{~m}^{2}$, sendo $1 \mathrm{~m}$ de largura por $8 \mathrm{~m}$ de comprimento, dotada de uma base constituída por 12 pilares em concreto armado e uma estrutura de madeira para a sustentação de telhas de fibrocimento onduladas com inclinação de 2,5\%. Este telhado inclinado possibilitou a recirculação da diluição da água produzida tratada nos ensaios experimentais.

$\mathrm{Na}$ bancada experimental (Figura 1), também, foi utilizado um reservatório de 0,31 $\mathrm{m}^{3}$ e um sistema de irrigação por gotejamento composto por um conjunto motobomba de 0,5 $\mathrm{cv}$, um filtro de tela de $130 \mu \mathrm{m}$, um registro de gaveta, um ponto para coleta de amostras, um manômetro analógico de glicerina da marca GE CI2.5 (graduado de 0 a $400 \mathrm{kPa}$ ), uma linha principal de $32 \mathrm{~mm}$, uma linha de derivação de $50 \mathrm{~mm}$ e nove linhas laterais com $8 \mathrm{~m}$ de comprimento, sendo três linhas laterais de cada tipo de emissor não autocompensante.

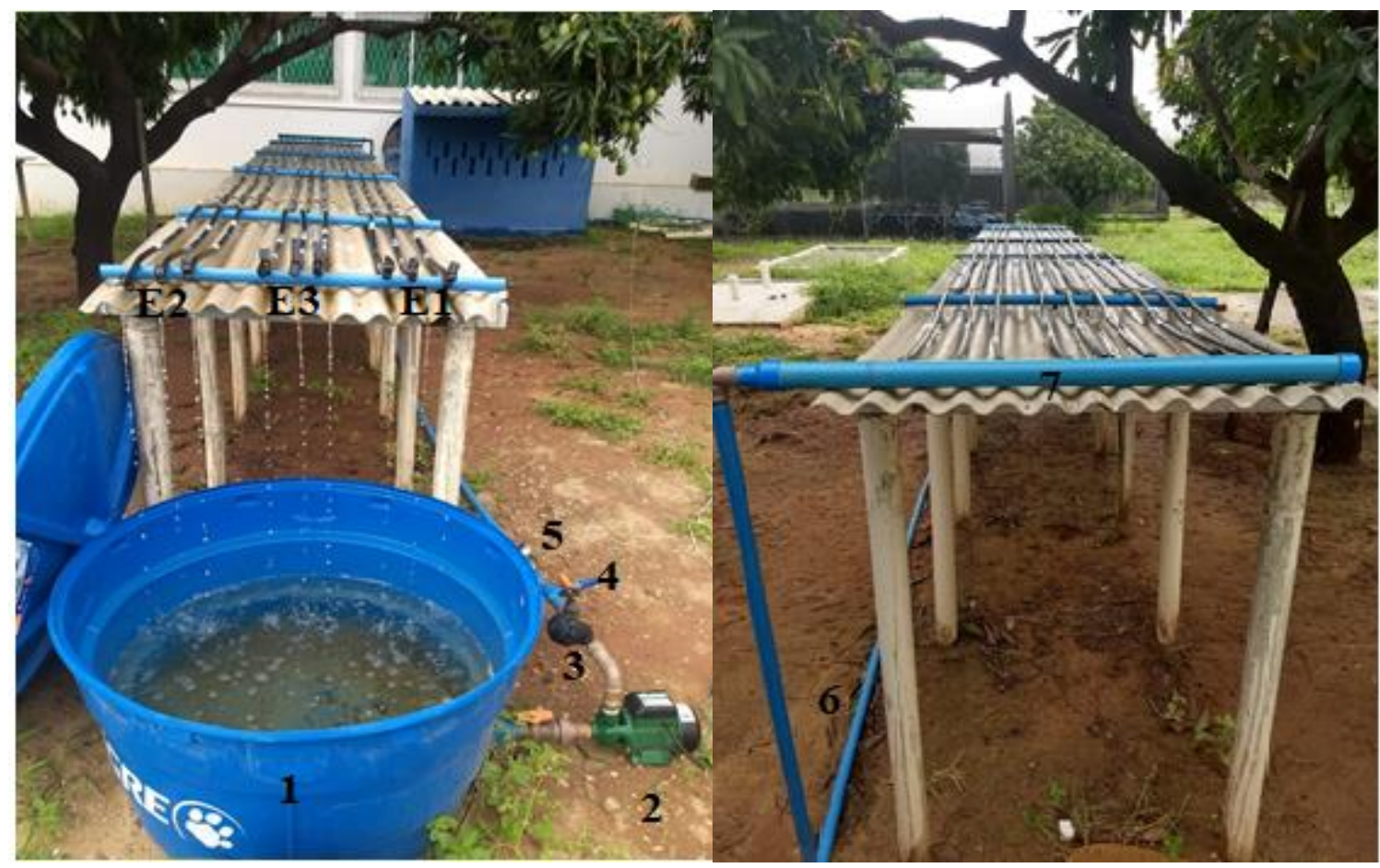

Figura 1. Imagens da bancada experimental dotada de três unidades gotejadoras, destacando os componentes: reservatório (1), motobomba (2), filtro (3), ponto de amostragem (4), manômetro analógico (5), linha principal (6), linha de derivação (7) e emissores não autocompensantes (E1, E2 e E3).

O sistema de irrigação por gotejo foi dividido em três unidades gotejadoras, distribuídas na bancada experimental de forma inteiramente casualizada, seguindo as recomendações de Marques et al. (2016).

Cada unidade gotejadora constou de três linhas laterais de $8 \mathrm{~m}$ de comprimento de um único tipo de emissor não autocompensante, onde em cada linha lateral foram selecionados 16 emissores para a avaliação dos níveis de obstrução e da alteração da vazão dos emissores. Na Tabela 2 estão apresentadas as especificações técnicas dos emissores não autocompensantes utilizados nos ensaios experimentais com diluição de água produzida tratada. 
Tabela 2. Especificações técnicas dos emissores não autocompensantes utilizados nas unidades gotejadoras que operação com diluição de água produzida tratada.

\begin{tabular}{ccccccccc}
\hline Fabricante & $\begin{array}{c}\mathrm{Q}^{*} \\
\left(\mathrm{~L} \mathrm{~h}^{-1}\right)\end{array}$ & $\mathrm{k}^{*}$ & $\mathrm{x}^{*}$ & $\begin{array}{c}\mathrm{A}^{*} \\
\left(\mathrm{~mm}^{2}\right)\end{array}$ & $\begin{array}{c}\mathrm{L}^{*} \\
(\mathrm{~mm})\end{array}$ & $\begin{array}{c}\mathrm{CVf}^{*} \\
(\%)\end{array}$ & $\begin{array}{c}\mathrm{P}^{*} \\
(\mathrm{kPa})\end{array}$ & $\begin{array}{c}\mathrm{EE}^{*} \\
(\mathrm{~m})\end{array}$ \\
\hline E1 - Netafim Super Typhoon & 1,60 & 0,53 & 0,48 & 34,0 & 23 & \pm 7 & $60-100$ & 0,30 \\
E2 - Netafim Streamline & 1,60 & 0,57 & 0,45 & 17,0 & 13 & \pm 7 & $65-100$ & 0,30 \\
E3 - NaanDanJainTal Drip & 1,70 & 0,56 & 0,46 & $6,0^{* *}$ & $44^{* *}$ & \pm 5 & $50-300$ & 0,20 \\
\hline
\end{tabular}

Nota: Q - Vazão nominal dos gotejadores na pressão de serviço de $100 \mathrm{kPa} ; \mathrm{k}$ - coeficiente de vazão; - expoente da vazão que caracteriza o regime de escoamento; A - Área de filtragem; L - Comprimento do labirinto; CVf - Coeficiente de variação de fabricação; P - Faixa de pressão recomendada; e EE - Espaçamento entre emissores. * Informações técnicas extraídas de catálogos dos fabricantes. ${ }^{* *}$ Informações obtidas com paquímetro digital com precisão de 0,01 mm. Fonte: Adaptado de Marques et al. (2016).

As unidades gotejadoras operaram, em média, quatro horas por dia até atingir o tempo de funcionamento de $160 \mathrm{~h}$, recomendado por Mesquita et al. (2016a,b), suficiente para que acarrete um nível de entupimento nos emissores que comprometa a vazão das unidades gotejadoras.

No período experimental de $160 \mathrm{~h}$ foram realizadas nove avaliações para as unidades gotejadoras, a cada $20 \mathrm{~h}$, resultando nos tempos de operação de $0,20,40,60,80,100,120,140$ e $160 \mathrm{~h}$, conforme proposto por Mesquita et al. (2016a,b).

Obteve-se a vazão de cada um dos 16 emissores selecionados por linha lateral, utilizando-se o valor do tempo de coleta de três minutos e o volume do efluente armazenado em recipientes de $200 \mathrm{~mL}$, nesse período. A quantificação desse volume foi efetuada em proveta de $100 \mathrm{~mL}$, com precisão de $1 \mathrm{~mL}$, conforme as especificações técnicas da NBR ISO 9261 (ABNT, 2006). Utilizou-se a Equação 1 para calcular a vazão dos emissores, ao longo do período experimental.

$$
\mathrm{Q}=\frac{\mathrm{v}}{1000 \cdot \mathrm{t}} \cdot 60
$$

Em que: Q - Vazão do emissor, $\mathrm{L} \mathrm{h}^{-1} ; \mathrm{v}$ Volume de efluente coletado, $\mathrm{mL}$; e t - Tempo de coleta do efluente, minutos.

A pressão de serviço foi mantida no valor de $100 \mathrm{kPa}$, para obter os valores de vazões nominais nos gotejadores ensaiados. Não houve precipitação pluviométrica no período em estudo.

Nos períodos de operação de 0,80 e 160 $\mathrm{h}$ efetuou-se a coleta de amostras da diluição da água produzida tratada, à jusante do sistema de filtração, para a realização de análises físicoquímicas e microbiológicas as quais seguiram as especificações do Standard Methods for the Examination of Water and Wastewater (BAIRD; EATON; RICE, 2017). À medida que a água produzida diluída evaporava, uma nova diluição na proporção de 1:10 era realizada para preencher o reservatório, o que poderia vir a ocasionar uma variação nas características físico-químicas e microbiológicas da água e, consequentemente, na obstrução dos gotejadores.

A Tabela 3 relaciona as características física, químicas e biológica presentes nas águas residuárias que podem ocasionar obstrução de emissores em sistemas de irrigação localizada.

No Laboratório de Análise de Solo, Água e Planta (LASAP) do Departamento de Ciências Agronômicas e Florestais (DECAF) da UFERSA foram determinados os valores de potencial hidrogeniônico $(\mathrm{pH})$, com pHmetro de bancada; dos teores de cálcio $(\mathrm{Ca} 2+)$ e magnésio $(\mathrm{Mg} 2+)$ pelo método titulométrico; das concentrações de ferro (Fe) e manganês $(\mathrm{Mn})$ por espectrofotometria de absorção atômica; e das concentrações de sólidos suspensos totais (SST) e de sólidos dissolvidos totais (SDT) pelo método gravimétrico. 
Tabela 3. Características física, químicas e biológica das águas residuárias para avaliação do potencial de entupimento dos gotejadores.

\begin{tabular}{|c|c|c|c|}
\hline \multirow{2}{*}{ Fatores de entupimento } & \multicolumn{3}{|c|}{ Níveis de risco } \\
\hline & Baixo & Moderado & Severo \\
\hline & & Físico & \\
\hline Sólidos suspensos totais ${ }^{\mathrm{a}}\left(\mathrm{mg} \mathrm{L}^{-1}\right)$ & $<50$ & $\frac{50-100}{\text { Ouímicos }}$ & $>100$ \\
\hline $\mathrm{pH}^{\mathrm{a}}$ & $<7,0$ & $7,0-7,5$ & $>7,5$ \\
\hline Sólidos dissolvidos totais ${ }^{\mathrm{a}}\left(\mathrm{mg} \mathrm{L}^{-1}\right)$ & $<500$ & $500-2000$ & $>2000$ \\
\hline Cálcio $^{\mathrm{b}}\left(\mathrm{mmol}_{\mathrm{c}} \mathrm{L}^{-1}\right)$ & $<12,5$ & $12,5-22,5$ & $>22,5$ \\
\hline Magnésio $^{\mathrm{b}}\left(\mathrm{mmol}_{\mathrm{c}} \mathrm{L}^{-1}\right)$ & $<2,0$ & $2,0-7,3$ & $>7,3$ \\
\hline Ferro total ${ }^{\mathrm{a}}\left(\mathrm{mg} \mathrm{L}^{-1}\right)$ & $<0,2$ & $0,2-1,5$ & $>1,5$ \\
\hline Manganês ${ }^{\mathrm{a}}\left(\mathrm{mg} \mathrm{L}^{-1}\right)$ & $<0,1$ & $0,1-1,5$ & $>1,5$ \\
\hline População bacteriana $^{\mathrm{a}}\left(\mathrm{NMP} 100 \mathrm{~mL}^{-1}\right)$ & $<10000$ & $\begin{array}{c}\text { Biológico } \\
10000-50000\end{array}$ & $>50000$ \\
\hline
\end{tabular}

Nota: (a) Segundo Bucks, Nakayama e Gilbert (1979) e ${ }^{\text {(b) }}$ De acordo com Capra e Scicolone (1998); NMP - número mais provável.

No Centro de Análises Clínicas e Imunológicas de Mossoró (CACIM) realizou a identificação e quantificação dos níveis populacionais dos coliformes totais nas amostras.

Os dados dos atributos físico-químicos e microbiológicos da diluição da água produzida tratada foram submetidos à análise descritiva, obtendo-se somente a média e o desvio-padrão.

Os dados de vazão dos emissores foram submetidos à análise de variância empregandose o teste $F(p \leq 0,01)$. Os modelos de regressão foram escolhidos com base na significância dos coeficientes da equação de regressão, pelo teste " $\mathrm{t}$ " ( $\mathrm{p} \leq 0,05)$, no valor do coeficiente de determinação $\left(R^{2} \geq 0,60\right)$ e no processo em estudo.

\section{RESULTADOS E DISCUSSÕES}

Na Tabela 4 observam-se os valores médios e desvio padrão dos atributos físicoquímicos e microbiológicos da diluição de água produzida e tratada, e respectiva classificação quanto ao risco de obstrução dos emissores.

Conforme relatado por Biscaro (2014) e Testezlaf (2017) os emissores, de sistemas de irrigação por gotejamento, são dispositivos altamente suscetíveis ao entupimento por agentes físicos, químicos e biológicos presentes na água de irrigação. Neste trabalho a água produzida tratada apresentou risco severo de obstrução de emissores para os atributos $\mathrm{pH}$, SDT e $\mathrm{Ca}^{2+}$, indicado que o risco entupimento por agentes químicos é maior do que o proporcionado por agentes físicos e biológicos. Já nos trabalhos de Mesquita et al. (2016a,b) com diluição de percolado de aterro sanitário, notou-se que os atributos SS e SDT foram os únicos que representaram risco severo de obstrução de emissores, corroborando parcialmente com os resultados deste trabalho.

$\mathrm{O}$ valor médio do $\mathrm{pH}$ do presente estudo foi semelhante a média de 7,56 encontrada por Miranda et al. (2016) na água produzida tratada por osmose reversa. Quanto ao risco de obstrução, o pH foi classificado como severo, devido a possibilidade de precipitação de sais (BUCKS; NAKAYAMA; GILBERT, 1979). Esse resultado é semelhante ao apresentado por Silva et al. (2017) que também afirmaram que o pH da água de irrigação representava um risco severo de obstrução de gotejadores. Corroborando, também, com o trabalho de Jiménez et al. (2017), onde o pH médio de 8,00 da água produzida estudada representou risco severo de obstrução emissores. 
Tabela 4. Caracterização físico-química e microbiológica da diluição da água produzida tratada, respectiva média, desvio padrão e classificação do risco de obstrução.

\begin{tabular}{|c|c|c|c|c|c|}
\hline \multirow{2}{*}{ Atributos } & \multicolumn{3}{|c|}{ Tempo de operação (h) } & \multirow{2}{*}{ Média e desvio padrão } & \multirow{2}{*}{$\begin{array}{l}\text { Risco de } \\
\text { obstrução }\end{array}$} \\
\hline & 0 & 80 & 160 & & \\
\hline $\mathrm{pH}$ & 7,10 & 7,79 & 7,74 & $7,54 \pm 0,38$ & Severo $^{(a)}$ \\
\hline $\mathrm{SST}\left(\mathrm{mg} \mathrm{L}^{-1}\right)$ & 45 & 80 & 50 & $58 \pm 18,93$ & Moderado $^{(a)}$ \\
\hline SDT (mg L $\left.{ }^{-1}\right)$ & 5405 & 5360 & 5490 & $5418 \pm 66,02$ & Severo ${ }^{\text {(a) }}$ \\
\hline $\mathrm{Ca}^{2+}\left(\mathrm{mmol}_{\mathrm{c}} \mathrm{L}^{-1}\right)$ & 28,83 & 75,20 & 80,25 & $61,43 \pm 28,34$ & Severo $^{(b)}$ \\
\hline $\mathrm{Mg}^{2+}\left(\mathrm{mmol}_{\mathrm{c}} \mathrm{L}^{-1}\right)$ & 1,63 & 3,65 & 2,55 & $2,61 \pm 1,01$ & Moderado $^{(b)}$ \\
\hline $\mathrm{Fe}\left(\mathrm{mg} \mathrm{L}^{-1}\right)$ & 0,168 & 0,034 & 0,062 & $0,088 \pm 0,071$ & Baixo $^{(a)}$ \\
\hline $\mathrm{Mn}\left(\mathrm{mg} \mathrm{L}^{-1}\right)$ & 0,069 & 0,046 & 0,037 & $0,051 \pm 0,017$ & Baixo $^{(a)}$ \\
\hline CT (NMP 100mL $\left.\mathrm{m}^{-1}\right)$ & $1 \times 10^{3}$ & $7,5 \times 10^{2}$ & $1,3 \times 10^{4}$ & $9,92 \times 10^{3} \pm 132^{(\mathrm{c})}$ & Baixo $^{(a)}$ \\
\hline
\end{tabular}

Nota: pH - Potencial hidrogeniônico; $\mathrm{Ca}^{2+}$ - Cálcio; $\mathrm{Mg}^{2+}$ - Magnésio; Mn - Manganês, $\mathrm{Fe}$ - Ferro; SST - Sólidos Suspensos Totais SDT - Sólidos Dissolvidos Totais; CT - Coliformes Totais; e NMP - Número Mais Provável. (a) Segundo Bucks, Nakayama e Gilbert (1979) e (b) De acordo com Capra e Scicolone (1998); (c) Média e desvio padrão geométrico.

A média de SST presente na água produzida tratada do presente trabalho foi superior a média de $10,6 \mathrm{mg} \mathrm{L}^{-1}$ apresentada por Dickhout et al. (2017). Analisando o valor médio de SST observou-se que, apesar das coletas das amostras terem sido realizadas após o sistema de filtragem, o risco de obstrução de gotejadores foi classificado como moderado (50 $\mathrm{mg} \mathrm{L}^{-1}<\mathrm{SST}<100 \mathrm{mg} \mathrm{L}^{-1}$ ) por Bucks, Nakayama e Gilbert (1979), indicando que a água produzida, apesar de diluída em água subterrânea, apresentava uma grande quantidade de sedimentos; divergindo do resultado encontrado por Vale et al. (2020) que obtiveram baixo risco de obstrução para o atributo SST, pelo fato da geologia de JucuriRN ser diferente de Upanema-RN.

Verificou-se pequena variação nas concentrações de SDT de 5360 a $5490 \mathrm{mg} \mathrm{L}^{-1}$, sendo a média aritmética de $5418 \mathrm{mg} \mathrm{L}^{-1}$. Esse valor foi superior ao limite de $2000 \mathrm{mg} \mathrm{L}^{-1}$, apresentado por Almeida (2010) como usual para água de irrigação, mas inferior ao valor médio de SDT apresentado por Miler et al. (2020) para água produzida. Em relação ao risco de obstrução dos emissores, o mesmo foi classificado como severo, pois o valor médio de SDT também foi superior ao valor limite de $2000 \mathrm{mg} \mathrm{L}^{-1}$ estabelecido por Bucks, Nakayama e Gilbert (1979). Este resultado difere, completamente, do encontrado por Vale et al. (2020), onde houve baixo risco de obstrução de emissores para o atributo SDT presente nas diluições contendo água produzida tratada.

Os teores de cálcio $\left(\mathrm{Ca}^{2+}\right)$ variaram de $28,83(0 \mathrm{~h})$ a $80,25 \mathrm{mmol}_{\mathrm{c}} \mathrm{L}^{-1}(160 \mathrm{~h})$, tendo média aritmética de 61,43 mmol $_{\mathrm{c}} \mathrm{L}^{-1}$ Essa elevação ao longo do tempo de operação pode ser consequência do aumento no $\mathrm{pH}$ da diluição. Esses valores foram bem superiores a maior taxa encontrada por Costa et al. (2019) na diluição de $25 \%$ de água produzida e $75 \%$ de água subterrânea em seu estudo água produzida tratada diluída da região de Jucuri-RN, onde os valores oscilaram de 0,96 a 1,77 mmol $_{\mathrm{c}} \mathrm{L}^{-1}$.

Com relação ao risco de obstrução dos emissores, o valor médio de $\mathrm{Ca}^{2+}$ foi superior ao limite de 22,50 $\mathrm{mmol}_{\mathrm{c}} \mathrm{L}^{-1}$ estabelecido por Capra e Scicolone (1998), sendo classificado como severo. Não corroborando com Vale et al. (2020) que obtiveram baixo risco de entupimento de emissores para o atributo $\mathrm{Ca}^{2+}$ presente nas diluições de água produzida tradada.

Quanto ao magnésio $\left(\mathrm{Mg}^{2+}\right)$, os valores oscilaram de 1,63 a 3,65 $\mathrm{mmol}_{\mathrm{c}} \mathrm{L}^{-1}$, sendo a média aritmética de 2,61 $\mathrm{mmol}_{\mathrm{c}} \mathrm{L}^{-1}$, durante o período de operação das unidades gotejadoras. De acordo com Almeida (2010), o teor médio de magnésio não atende aos padrões para água de irrigação, pois é superior ao limite de 2,5 mmolc L ${ }^{-1}$.

Analisando o valor médio do $\mathrm{Mg}^{2+} \mathrm{e}$ utilizando a classificação de Capra e Scicolone (1998), constatou-se que o risco de 
entupimento de emissores foi moderado (2,0 mmol $_{\mathrm{c}} \mathrm{L}^{-1}<\mathrm{Mg}^{2+}<7,3$ mmol $\left._{\mathrm{c}} \mathrm{L}^{-1}\right)$.

No trabalho de Vale et al. (2020) com diluições de água produzida tratada, o risco de obstrução para $\mathrm{Mg}^{2+}$ foi classificado como baixo, divergindo do resultado encontrado no presente estudo.

Em relação ao ferro $(\mathrm{Fe})$ os valores oscilaram de 0,034 a $0,168 \mathrm{mg} \mathrm{L}^{-1}$, tendo média aritmética de $0,088 \mathrm{mg} \mathrm{L}^{-1}$, divergindo dos valores de $\mathrm{Fe}$ encontrado por Andrade et al. (2011) Notou-se baixo risco de entupimento de emissores em relação ao teor médio de $\mathrm{Fe}\left(\mathrm{Fe}<0,2 \mathrm{mg} \mathrm{L}^{-1}\right)$, quando se utiliza a classificação de Bucks, Nakayama e Gilbert (1979).

Para o manganês (Mn) os valores variaram de 0,037 a $0,069 \mathrm{mg} \mathrm{L}^{-1}$, tendo média aritmética de $0,051 \mathrm{mg} \mathrm{L}^{-1}$, média essa inferior a de $0,002 \mathrm{mg} \mathrm{L}^{-1}$ encontrado por Weber et al. (2017) em água produzida tratada por filtração no município de Aracati-CE.

$\mathrm{O}$ teor médio de $\mathrm{Mn}$ foi inferior ao valor limite de $0,1 \mathrm{mg} \mathrm{L}^{-1}$, classificando o risco de obstrução de emissores como baixo (BUCKS; NAKAYAMA; GILBERT, 1979).
Os níveis populacionais de coliformes totais (CT) oscilaram de 7,50 x10 ${ }^{2}$ a $1,30 \times 10^{4}$ NMP $100 \mathrm{~mL}^{-1}$, sendo a média geométrica de $9,92 \times 10^{3}$. Com relação ao risco de obstrução de emissores, o mesmo foi baixo segundo a classificação de Bucks, Nakayama e Gilbert (1979). De acordo com Baird, Eaton e Rice (2017), o grupo CT engloba as bactérias dos gêneros Klebsiella e Enterobacter capazes de produzir mucilagens que obstruem emissores (BUCKS; NAKAYAMA; GILBERT, 1979).

Na Tabela 5 consta a análise de variância da vazão das unidades gotejadoras, ao longo do tempo de operação de 160 h, utilizando diluição de água produzida tratada. Constatou-se a interação tipos de emissores versus tempo de operação foi significativa a $1 \%$ de probabilidade pelo teste $\mathrm{F}$, indicando que as vazões das unidades gotejadoras foram alteradas de forma significativa, ao longo do tempo de operação e entre os tipos de emissores; fato esse reforçado quando se analisa separadamente tipo de gotejador e tempo de operação e evidencia-se também alteração significativa da vazão para essas fontes de variação.

Tabela 5. Análise de variância da vazão de três emissores não autocompensantes, aplicando diluição de água produzida tratada durante $160 \mathrm{~h}$ de operação, na pressão de serviço de $100 \mathrm{kPa}$.

\begin{tabular}{ccc}
\hline Fontes de variação & Graus de liberdade & Quadrado médio \\
\hline Tipos de emissores (TE) & 2 & $1,30^{* *}$ \\
Resíduo (a) & 4 & 0,030 \\
Tempos de operação (TO) & 8 & $0,021^{* *}$ \\
TE x TO & 16 & $0,013^{* *}$ \\
Resíduo (b) & 50 & 0,0043 \\
Coeficiente de variação da parcela (\%) & & 12,89 \\
Coeficiente de variação da subparcela (\%) & & 4,86 \\
\hline
\end{tabular}

Nota: ${ }^{* *}$ Significativo a $1 \%$ de probabilidade pelo Teste F.

Estes resultados corroboram com os encontrados por Fernandes et al. (2014) que obtiveram, também, em sua análise de variância, interação significativa a $1 \%$ de probabilidade pelo teste $\mathrm{F}$ para as fontes de variação tipos de emissores, tempo de operação e a interação tipo de emissores versus tempo de operação.

Os valores dos coeficientes de variação foram de 12,89 e 4,86\%, para a parcela e subparcela, sendo classificados por Pimentel Gomes (2009) como médio $(10 \%<\mathrm{CV}<20 \%)$ e baixo $(\mathrm{CV}<10 \%)$, respectivamente. Porém, esses resultados foram superiores aos valores de 1,44 e 2,20\% obtidos por Fernandes et al. (2014) em seu estudo com a alteração da vazão de emissores utilizando água residuária oriunda do processo de industrialização da castanha de caju. 
Observou-se, na Figura 2A, que a vazão média do emissor Netafim Super Typhoon-E1 foi de 1,57 e $1,60 \mathrm{~L} \mathrm{~h}^{-1}$, nos tempos de operação inicial $(0 \mathrm{~h})$ e final $(160 \mathrm{~h})$, respectivamente. Percebeu-se, ao longo do período experimental, redução da vazão às $20,40,60,100$ e 140 h e aumento da vazão às 80,120 e $160 \mathrm{~h}$. Ressaltase que a máxima redução da vazão de $11,34 \%$ ocorreu às $40 \mathrm{~h}$, enquanto o máximo aumento de vazão de $2,42 \%$ aconteceu às $160 \mathrm{~h}$. Este resultado difere do obtido por Cunha et al. (2017) com diluição de efluente de laticínios aplicado por unidades gotejadoras durante 200 $\mathrm{h}$, onde o mesmo emissor E1 apresentou máxima redução de vazão de $10,49 \%$ às $160 \mathrm{~h}$ e não apresentou aumento de vazão.

A

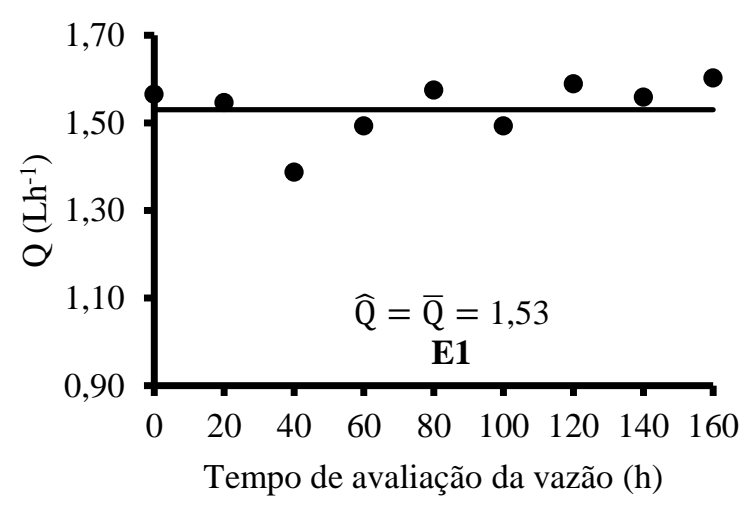

B

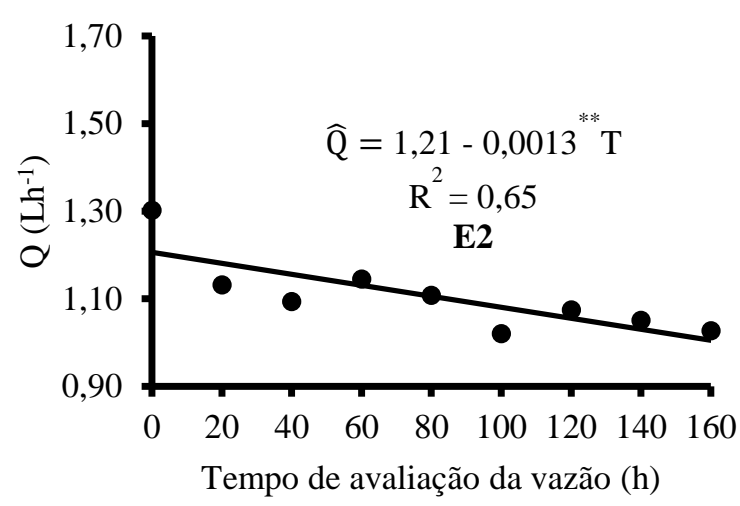

C

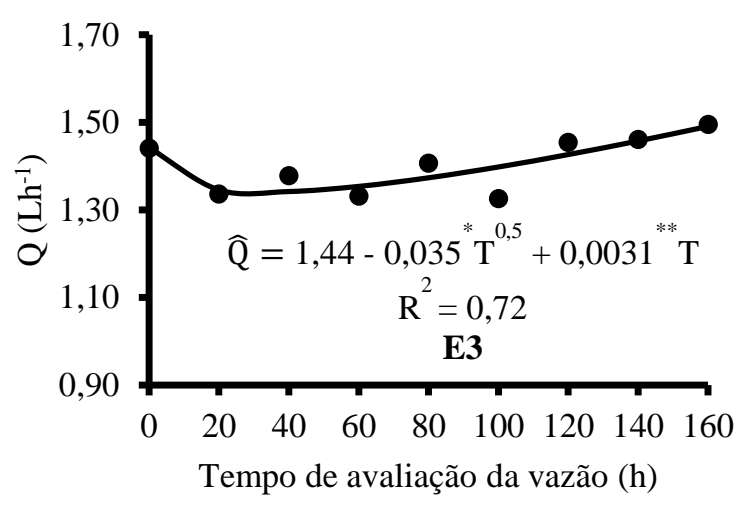

Figura 2. Valores médios da vazão (Q) dos emissores Netafim Super Typhoon-E1 (A), Netafim Streamline-E2 e NaanDanJain TalDrip-E3, ao longo do período da operação das unidades gotejadoras sob pressão de serviço de $100 \mathrm{kPa}$, abastecidas com diluição da água produzida do petróleo tratada e respectivas equações de regressão. Nota: **e * Significativo a 1 e $5 \%$ de probabilidade pelo teste " $\mathrm{t}$ ", respectivamente. 
Ainda na unidade gotejadora E1, a média ajustou-se melhor a relação entre os dados de vazão $(Q)$ e tempo de operação $(T)$, indicando maior resistência ao entupimento desse emissor ao operar com diluição de água produzida tratada, em relação ao emissor Netafim Streamline-E2, provavelmente devido a sua maior área de filtragem (Tabela 1). Corroborando com os resultados do trabalho de Marques et al. (2016) com diluição de efluente de laticínios, onde a média foi melhor ajuste para a relação Q e T para o mesmo emissor E1. Já no trabalho realizado por Silva et al. (2019), também com o emissor E1 aplicando águas residuária doméstica tratada durante $400 \mathrm{~h}$, o modelo de regressão que melhor se ajustou aos dados de $\mathrm{Q}$ e $\mathrm{T}$ foi o cúbico, que difere do resultado do presente estudo.

Evidenciou-se, na Figura 2B, que a vazão média do emissor Netafim Streamline-E2 decresceu ao longo do período experimental. $\mathrm{Na}$ unidade gotejadora E2, o modelo linear foi o que melhor representou a relação entre os dados de $\mathrm{Q}$ e $\mathrm{T}$, tendo coeficiente de determinação de 0,65 e coeficiente angular da reta de 0,0013 que indica a velocidade do processo de obstrução. Divergindo tanto do resultado apresentado por Silva et al. (2019), onde a média foi a melhor representação da relação entre $\mathrm{Q}$ e $\mathrm{T}$, quando da aplicação de água residuária doméstica tratada durante $400 \mathrm{~h}$ de operação das unidades gotejadoras, quando do trabalho de Marques et al. (2016) que ajustou o modelo raiz quadrada a relação Q e T para o emissor E2 aplicando diluição de efluente de laticínios.

$\mathrm{Na}$ Figura 2C, notou-se que a vazão média do NaanDanJain TalDrip-E3 decresceu às $20,40,60,80$ e $100 \mathrm{~h}$ e aumentou às 120 , 140 e 160 h, em relação à vazão média inicial (0h) de 1,44 $\mathrm{L} \mathrm{h}^{-1}$. A máxima redução de vazão de 7,95\% aconteceu às $100 \mathrm{~h}$, enquanto o máximo aumento de vazão de $3,79 \%$ ocorreu às 160 h. No trabalho desenvolvido por Cunha et al. (2017), o emissor E3 apresentou apenas redução da vazão ao longo do período experimental, quando utilizado na aplicação de diluição de efluente de laticínios.
No trabalho desenvolvido por Cunha et al. (2020), o emissor E3, também, foi o mais resistente ao entupimento, dentre os três emissores estudados mediante aplicação de águas com distintas temperaturas e salinidades durante $750 \mathrm{~h}$ de operação das unidades gotejadoras.

A relação entre os dados de $\mathrm{Q}$ e $\mathrm{T}$ foi melhor representada no modelo raiz quadrada na unidade gotejadora E3, tendo coeficiente de determinação de 0,72. Nesse modelo de regressão, a constante positiva que multiplica a componente linear de $\mathrm{T}$, representa o aumento de vazão ao longo de parte do período experimental. Divergindo do resultado encontrado por Marques et al. (2016), onde o mesmo emissor E2 apresentou relação quadrática entre os dados de Q e T ao aplicar diluição de efluente de laticínios.

As oscilações (aumento e redução) nos valores de Q, ao longo do tempo de operação do sistema, podem ter ocorrido em razão da desobstrução espontânea devido ao aumento de temperatura durante determinado período, acarretando o desprendimento da incrustação das paredes do labirinto (CUNHA et al., 2006), como, também, à sobrelevação da pressão de serviço ocorrida em função da obstrução parcial dos gotejadores, como evidenciado por Faria et al. (2002). Nos trabalhos de Vale et al. (2018a,b) com diluição de percolado de aterro sanitário, verificou-se que a obstrução variou ao longo do tempo de operação em função das características construtivas dos emissores, o que também foi evidenciado no presente trabalho.

Dentre os três emissores estudados, o emissor E2 foi o mais suscetível ao entupimento, apresentando máxima redução de vazão de $21,61 \%$ às $100 \mathrm{~h}$. Esse fato pode ser atribuído aos agentes ocasionadores de obstrução, principalmente $\mathrm{pH}$, SDT e $\mathrm{Ca}^{2+}$ (Tabela 4), como também ao menor comprimento de labirinto, conforme relatado por Liu e Huang (2009). Esses autores concluíram que o gotejador com menor labirinto e menor vazão, apresentou maior suscetibilidade ao entupimento. 
O emissor E3 apresentou a menor redução máxima de vazão em relação aos emissores E1 e E2, revelando maior resistência ao entupimento em relação a esses dois tipos de emissores, provavelmente em função do seu menor coeficiente de variação de fabricação, quando da aplicação de diluição de água produzida tratada.

\section{CONCLUSÕES}

Dentre as características físico-químicas e biológica da água produzida tratada diluída, apenas o pH, cálcio e sólidos dissolvidos totais representaram risco severo de entupimento de gotejadores com agentes químicos.

A maior suscetibilidade ao entupimento foi verificada para o gotejador E2, devido, provavelmente, ao seu menor comprimento de labirinto aliado à formação de incrustação no gotejador.

O gotejador E3 é o mais recomendado na operação com água produzida tratada diluída, na proporção de 1:10 (uma parte de água produzida tratada para 10 partes de água subterrânea).

Os modelos de regressão linear e raiz quadrada foram os que melhor se ajustaram à relação entre a variável Q em função do tempo de operação das unidades de irrigação.

\section{REFERÊNCIAS}

ANDRADE, B. G.; ANDRADE, V. T.; COSTA, B. R. S.; CAMPOS, J. C.; DEZ, M. Distillation of oil field produced water for reuse on irrigation water: evaluation of pollutants removal and ecotoxicity. Journal of Water Reuse and Desalination, v. 1, p.224-236, 2011. https://doi.org/10.2166/wrd.2011.044

\footnotetext{
ASSOCIAÇÃO BRASILEIRA DE NORMAS TÉCNICAS (ABNT). Equipamentos de irrigação agrícola - Emissores e tubos emissores - Especificações e métodos de ensaio. ABNT NBR ISO 9261, São Paulo: ABNT, 17p. 2006.
}

BAIRD, R. B.; EATON, A. D.; RICE, E. W. Standard methods for the examination of water and wastewater. 23.ed. Washington: APHA, AWWA, WPCR, 2017. 1504p.

BISCARO, G. A. Sistemas de irrigação localizada. Dourados: UFGD, 2014. 256p.

BUCKS, D. A.; NAKAYAMA, F. S.; GILBERT, R. G. Trickle irrigation water quality and preventive maintenance. Agricultural Water Management, v.2, n.2, p. 149-162, 1979. https://doi.org/10.1016/03783774(79)90028-3.

CAPRA, A.; SCICOLONE, B. Water quality and distribution uniformity in drip/trickle irrigation systems. Journal of Agricultural Engineering Research, v.70 n.4, p.355-365, 1998. https://doi.org/10.1006/jaer.1998.0287.

COSTA, D. O.; VALE, H. S. M.; BATISTA, R. O.; TRAVASSOS, K. D.; PORTELA, J. C. Chemical characteristics of soil irrigated with produced water treatment and underground water. Revista Dyna, v.86, n.210, p. 143-149, 2019.https://doi.org/10.15446/dyna.v86n210.7 9115.

CUNHA, J. L. O.; SILVA, S. L.; BATISTA, R. O.; MARQUES, B. C. D.; COELHO, D. C. L.; SILVA, B. S. Monitoramento da bioincrustação em fitas gotejadoras aplicando água com distintas temperaturas e salinidades. Irriga, v.25, n.1, p. 1-13, 2020. https://doi.org/10.15809/irriga.2020v25n1p113.

CUNHA, F. F.; MATOS, A. T.; BATISTA, R. O.; LO MONACO, P. A. Uniformidade de distribuição em sistemas de irrigação por gotejamento utilizando água residuária da despolpa dos frutos do cafeeiro. Acta Scientiarum. Agronomy, v.28, n.1, p.143147, 2006.https://doi.org/10.4025/actasciagron.v28i1.1706.

CUNHA, M. E.; MARQUES, B. C. D.; BATISTA, R.O.; COSTA, A. G.; CUNHA, R. 
R.; ANDRADE, A. T. S. Obstrução de gotejadores operando com efluente de laticínios diluído. Revista Brasileira de Agricultura Irrigada, v.11, n.4, p. 1517-1527, 2017. https://doi.org/ 10.7127/rbai.v11n400644.

DICKHOUT, J. M.; MORENO, J.; BIESHEUVEL, P.M.; BOELS, L.; LAMMERTINK, R.G.H.; VOS, W. M. Produced water treatment by membranes: a review from a colloidal perspective. Journal of Colloid and Interface Science, v. 487, p. 523534, 2017. https://doi.org/10.1016/j.jcis.2016.10.013

FARIA, L. F.; COELHO, R. D.; FLECHA, P. A. N.; ROBLES, W. G. R.; VÁSQUEZ, M. A. N. Entupimento de gotejadores e seu efeito na pressão da rede hidráulica de um sistema de microirrigação. Revista Brasileira de Engenharia Agrícola e Ambiental, v.6, n.2, p.195-198, 2002. https://doi.org/10.1590/S14154366200200020 0002.

FERNANDES, R. K. A.; BATISTA, R. O.; COSTA, S. K.; OLIVEIRA, J. F.; PAIVA, L. A. L. Vazão de gotejadores aplicando água residuária da castanha de caju. Irriga, v.19, n.4, p. 585-597, 2014. https://doi.org/10.15809/irriga.2014v19n4p58 5.

JIMÉNEZ, S.; MICÓ, M. M.; ARNALDOS, M.; FERRERO, E.; MALFEITO, J. J., MEDINA, F.; CONTRERAS, S. Integrated processes for produced water polishing: Enhanced flotation/sedimentation combined with advanced oxidation processes. Chemosphere, v. 168, p. 309-317, 2017. https://doi.org/10.1016/j.chemosphere.2016.10 .055

LIU, H.; HUANG, G. Laboratory experiment on drip emitter clogging with fresh water and treated sewage effluent. Agricultural Water Management, v.96, n.5, p.745-756, 2009. https://doi.org/10.1016/j.agwat.2008.10.014.
MARQUES, B. C. D; CUNHA, V. T; CUNHA, V. T; SILVA, K. B; BATISTA, R. O. Desempenho de gotejadores operando com água residuária de laticínios em escala laboratorial. Irriga, v.21, n.1, p. 140-155, 2016.

https://doi.org/10.15809/irriga.2016v21n1p14 $0-155$.

MESQUITA, F.O.; ALVES, S. M. C.; BATISTA, R. O.; DANTAS, T. B.; SOUZA, L. Desempenho de gotejadores aplicando percolado de aterro sanitário diluído. Irriga, v. $21, \quad$ n. $1, \quad$ p. 156-171, 2016a. https://doi.org/10.15809/irriga.2016v21n1p15 6-171.

MESQUITA, F. O.; ALVES, S. M. C.; BATISTA, R. O.; DANTAS, T. B.; DI SOUZA, L. Drip units operating with dilute landfill leachate. Revista Caatinga, v.29, n.1, p. $163 \quad$ - $172, \quad 2016$ b. https://doi.org/10.1590/198321252016v29n119rc.

MILLER, H.; DIAS, K.; HARE, H.; BORTON, M. A.; BLOTEVOGEL, J.; DANFORTH, C.; WRIGHTON, K. C.; IPPOLITO, J. A.; $\mathrm{BORCH}, \mathrm{T}$. Reusing oil and gas produced water for agricultural irrigation: Effects on soil health and the soil microbiome. Science of The Total Environment, v. 722, 137888, 2020. https://doi.org/10.1016/j.scitotenv.2020.13788 8.

MIRANDA, F. R.; CRISOSTOMO, L. A.; WEBER, O. B.; SILVA, F. L. B.; ARAGÃO, F. A. S.; BARROS, M. E. S. Irrigação com água produzida na extração de petróleo: efeitos sobre a salinidade do solo e a produtividade da mamoneira. Fortaleza: Embrapa Agroindústria Tropical, 2016.29 p.

PIMENTEL GOMES, F. Curso de estatística experimental. 15. ed. Piracicaba: FEALQ, 2009. $451 \mathrm{p}$.

SILVA, K. B.; BATISTA, R.O.; COELHO, D. 
C. L.; MARQUES, B. C. D.; MESQUITA, F.O.; CUNHA, J. L. O. Vazão de gotejadores aplicando esgoto sanitário tratado e prevenção do entupimento com catalisador enzimático. Revista em Agronegócio e Meio Ambiente, v.12, n.2, p. 679-699, 2019. https://doi.org/10.17765/21769168.2019v12n2p679-699.

SILVA, P. F.; MATOS, R. M.; LIMA, S. C.; DANTAS NETO, J.; LIMA, V. L. A. Obstruction and uniformity in drip irrigation systems by applying treated wastewater Revista Ceres, v.64, n.4, p.344-350, 2017. https://doi.org/10.1590/0034737x2017640400 02.

TESTEZLAF, R. Irrigação: métodos, sistemas e aplicações. Campinas-SP: Unicamp/Feagri, 215p. 2017.

VALE, H. S. M.; BATISTA, R.O.; COSTA, D. O.; LEMOS FILHO, L. C. A.; SANTOS, D. B.; SILVA, P. C. M. Detecção do entupimento em gotejadores aplicando percolado de aterro sanitário diluído. Revista em Agronegócio e Meio Ambiente, v.11, n.3, p. 975-993, 2018a. http://dx.doi.org/10.17765/21769168.2018v11 n3p975-993.

VALE, H. S. M.; COSTA, D. O.; BATISTA, R. O.; COELHO, D. C. L.; FEITOSA,
A. P. Hydraulic performance of drippers applying sanitary landfill leachate diluted in water. Revista Caatinga, v.31, n.4, p.987-996, 2018b.

https://doi.org/10.1590/198321252018v31n42 2rc.

VALE, H. S. M.; COSTA, D. O.; BATISTA, R. O.; OLIVEIRA, F. A.; MEDEIROS, J. F.; COELHO, D. C. L. Distribution uniformity in drip units applying dilutions of treated water produced by oil exploration. Revista Brasileira de Engenharia Agrícola e Ambiental, v.24, n.6, p.304-401, 2020. http://dx.doi.org/10.1590/18071929/agriambi. v24n6p394-401.

WEBER, O. B.; CRISOSTOMO, L. A.; MIRANDA, F. R.; SOUSA, A. F.; MESQUITA, A. L. M.; CABRAL, J. E. O. Production of ornamental sunflower irrigated with oilfield produced water in the Brazilian semiarid region. Pesquisa Agropecuária Brasileira, v. 52, n. 6, p.443-454, 2017. http://dx.doi.org/10.1590/s0100204x20170006 00008. 